\title{
APPLICATION OF VOCABULARY TO CHILDREN WITH EDUCATIONAL GAMES
}

\author{
Rahmawati \\ Universitas Indraprst PGRI \\ Somawati \\ Universitas Indraprst PGRI \\ J1. Nangka no 58 C Tanjung Barat Jagakarsa Jakarta Selatan \\ e-mail: rhmarisma10@gmail.com
}

\begin{abstract}
Professionalism of a teacher is not only required to teach well, but can guide the development of children, especially in the application of vocabulary in early childhood, because not all children at an early age can apply vocabulary properly and correctly. This study aims to apply vocabulary to children using educational games (APE). This type of research used quantitative descriptive, as a sample of 18 students of TK AL-AFLAH, data collection using a survey. The formulation of the problem in this research is How difficult are the teachers in guiding children towards learning, especially in applying vocabulary to children. The results showed that the application of vocabulary in children with educational play tools increased, so that the learning process could be optimal with educational play tools that were able to stimulate all early childhood development.
\end{abstract}

Key Words: Vocabulary, early childhood, educational play tools (APE)

Article History: Received: 25/09/2020; Revised: 26/10/2020; Accepted: 30/11/2020; Published: 31/12/2020

How to Cite (MLA 7 ${ }^{\text {th }}$ : Rahmawati and Somawati. "Application of Vocabulary to Children with Educational Games." Hortatori Jurnal Pendidikan Bahasa dan Sastra Indonesia 4.2 (2020): 150-154. Print/Online. Copyrights Holder: Rahmawati, Somawati. First Publication: Hortatori Jurnal Pendidikan Bahasa dan Sastra Indonesia (2020).

This work is licensed under a Creative Commons Attribution-ShareAlike 4.0 International License.

\section{Pendahuluan}

Pada dasarnya penerapan kosakata adalah salah satu komponen pembelajaran Bahasa. Kosakata atau pembendaharaan kata sangatlah penting dimiliki oleh anak-anak (Markus et al.). Dengan demikian diketahui bahwa kosakata pada anak sangatlah penting karena bahasa itu sendiri merupakan alat untuk berkomunikasi(Khotijah).

Dalam kehidupan berbahasa seseorang, kosakata memiliki kiprah yang sangat penting, baik berbahasa menjadi proses berpikir juga menjadi indera komunikasi pada masyarakat (Suhendi). Kosakata adalah indera utama yang dimiliki seorang yang akan belajar bahasa lantaran kosakata berfungsi untuk menciptakan kalimat, mengutarakan isi pikiran dan perasaan menggunakan paripurna baik secara verbal juga tulisan.

Kosakata yaitu (1) seluruh istilah yang masih ada pada suatu bahasa (2) istilah-istilah yang dikuasai oleh seorang atau sekelompok orang menurut lingkungan yang sama (3) Sejumlah istilah menurut suatu bahasa yang disusun secara alfabetis bersama menggunakan sejumlah penerangan maknanya (Santoso).

Bahasa adalah indera komunikasi menjadi wahana yang sangat krusial pada kehidupan anak usia dini (Krisnawan). Pendidikan anak usia dini (PAUD) adalah suatu planning yang dilakukan pada anak yang usianya 0-6 tahun menggunakan hadiah rangsangan pendidikan untuk membantu setiap tumbuh kembangnya baik jasmani juga rohani, dan mempersiapkan kesiapan mereka untuk menempuh pendidikan lebih lanjut (Nurmadiah). 
Sesuai dengan Undang-Undang Nomor 20 tahun 2003 dalam (Hapidin) tentang sistem pendidikan nasional, dalam pasal 1 butir 14 pendidikan anak usia dini (Paud) diartikan sebagai: Suatu upaya training yang ditujukan pada anak semenjak lahir hingga menggunakan usia enam tahun yang dilakukan melalui anugerah rangsangan pendidikan buat membantu pertumbuhan dan perkembangan jasmani dan rohani supaya anak mempunyai kesiapan pada memasuki pendidikan lebih lanjut.

Alat Permainan Edukatif (APE) adalah indera permainan yang didesain dan dibentuk untuk sebagai muara belajar anak usia dini supaya menerima pengalaman belajar. (Sahjat and Samad) Menurut Sudjana dalam (Kuncoro et al.)APE merupakan suatu alat yang dapat diserap oleh mata dan telinga yang bertujuan membantu guru agar proses belajar mengajar siswa lebih efektif dan efisien.

Direktorat PADU, Depdiknas (2003) dalam (Nur et al.)mendefinisikan indera permainan edukatif menjadi segala sesuatu yang bisa dipakai menjadi wahana atau alat-alat buat bermain yang mengandung nilai edukatif (pendidikan) dan bisa menyebarkan semua kemampuan anak.

Jadi, definisi indera permainan edukatif dari para ahli, indera ini adalah sebuah indera bantu yang digunakan pada proses edukasi atau belajar mengajar yang berperan akbar menjadi pendukung aktivitas pembelajaran yang dilakukan sang pendidik atau guru. Alat ini dipakai buat mengungkapkan konsep-konsep suatu materi yang bersifat tak berbentuk atau samar-samar supaya terlihat konkret dan jelas.

Berdasarkan hasil survei penelitian. (Oktavianingsih) dalam penerapan kosakata bahasa pada anak usia dini masih kurang lantaran peran orang tua dan lingkungan keluarga dalam menstimulus kemampuan bahasa anak belum maksimal, kurangnya penerapan kosakata bahasa anak usia dini pada Taman Kanak-kanak Al-Aflah ini maka penulis melakukan penelitian mengenai penerapan kosakata bahasa pada anak usia dini menggunakan alat permainan edukatif (APE).

Rumusan masalah pada penelitian ini, yaitu bagaimana kesulitan guru dalam membimbing anak terhadap pembelajaran khususnya dalam penerapan kosakata pada anak usia dini menggunakan alat permainan edukatif (APE). Selama proses observasi dan wawancara dengan kepala sekolah, mereka menceritakan dan mengungkapkan masalah mereka. Kurangnya kosakata bahasa dalam anak usia dini dan alat permainan edukatif, sehingga penerapan kosakata pada anak dengan alat permainan edukatif mampu menstimulus seluruh perkembangan anak usia dini.

\section{Metode}

Penelitian ini menggunakan metode kuantitatif yaitu dengan pendekatan deskripsi, pada awal penelitian di lakukan persiapan dengan studi pendahuluan, pengumpulan data, analisis data dan penarikan kesimpulan.

Analisis data menggunakan hasil survei, penyajian data, interprestasi data dan penarikan kesimpulan. Subjek penelitian ini adalah siswa TK AL-AFLAH dengan jumlah responden yang terkumpul sebanyak 18 siswa.

\section{Hasil dan Diskusi}

Dalam peningkatan kosakata bahasa dalam anak usia dini menggunakan indera permainan edukatif (APE) banyak hal yang wajib dipahami sang pengajar dan orang tua, lantaran bahasa berperan krusial bagi kehidupan oleh karenanya pentingnya kosakata bahasa dalam anak usia dini wajib dibina dan distimulasikan sebaik-baiknya.

Tabel 1. Indikator Penerapan Kosakata Bahasa pada Anak Usia Dini (3-4) Tahun dengan Alat Permainan Edukatif (APE) di TK Al-AFLAH

\begin{tabular}{lll}
\hline Lingkungan Perkembangan Anak & Tingkatan Perkembangan Anak TK (3-4) tahun \\
\hline A. Konsep bentuk, warna, berukuran dan pola & $1 . \quad$ Mengklasifikasikan benda berdasarkan Mengklasifikasikan benda \\
& & dari warna, bentuk dan berukuran (tiga variasi) \\
B. Konsep bilangan, lambang bilangan, dan huruf & 1. Mengenal pola ABCD- ABCD \\
& $2 . \quad$ Menyebutkan lambang angka 1-10 \\
\hline
\end{tabular}

Sumber: Peraturan Menteri Pendidikan Nasional No:58 th 2009, Standar Pendidikan Nasional Anak Usia Dini (Direktorat Pembinaan TK dan SD 2009). 
Pada awalnya, dari analisis data menggunakan survei ternyata pengajar sudah melakukan aneka macam usaha menggunakan pemberian stimulus dan bimbingan juga melakukan assesmen terhadap pembelajaran anak hasilnya belum maksimal. Akan tetapi setelah peneliti melakukan penelitian dengan menerapkan kosakata bahasa pada anak usia dini dengan permainan edukatif (APE) hasilnya sangat memuaskan. Hal ini dapat dilihat pada tabel berikut:

Tabel 2. Data hasil survei Penerapan Kosakata Bahasa pada Anak Usia Dini dengan Alat Permainan Edukatif (APE) di TK Al-AFLAH, Jagakarsa. Jakarta-Selatan.

\begin{tabular}{|c|c|c|c|c|c|c|}
\hline \multirow{2}{*}{ No. } & \multirow[t]{2}{*}{ Nama } & \multicolumn{3}{|c|}{ Perkembangan } & & \multirow[t]{2}{*}{ Penilaian } \\
\hline & & 1 & 2 & 3 & & \\
\hline 1. & Chila & $\mathrm{BM}$ & MM & MM & MM & MM \\
\hline 2. & Ammar & MM & MM & MSH & MSH & MSH \\
\hline 3. & Abhinaya & $\mathrm{BM}$ & MM & MM & MM & MM \\
\hline 4. & Haikal & MM & MSH & MSH & MSH & MSH \\
\hline 5. & Farah & MSH & MSH & MSH & MSH & MSH \\
\hline 6. & Shafiq & MM & MM & MM & MM & MM \\
\hline 7. & Alesha & $\mathrm{BM}$ & MM & MM & MM & MM \\
\hline 8. & Zizi & MM & MM & MM & MM & MM \\
\hline 9. & Shena & MM & MSH & MSH & MSH & MSH \\
\hline 10. & Azka & MSH & MSH & MSH & MSH & MSH \\
\hline 11. & Barra & MM & MSH & MSH & MSH & MSH \\
\hline 12. & Aimar & MM & MM & MM & MM & MM \\
\hline 13. & Najla & MSH & MSH & MSH & MSH & MSH \\
\hline 14. & Alisha & MM & MM & MM & MM & MM \\
\hline 15. & Jaden & MSH & MSH & $\mathrm{MSH}$ & MSH & MSH \\
\hline 16. & Hadyan & MM & MSH & MSH & MSH & MSH \\
\hline 17. & Aqilah & MSH & MSH & MSH & MSH & MSH \\
\hline 18. & Bilqis & $\mathrm{MSH}$ & MSH & $\mathrm{MSH}$ & MSH & MSH \\
\hline
\end{tabular}

Keterangan Huruf:

BM : Belum Meningkat

MM : Mulai Meningkat

MSH : Meningkat sesuai Harapan

Keterangan Angka:

1. Mengklasifikasikan benda dari warna, bentuk dan ukuran (tiga variasi)

2. Mengenal pola ABCD- ABCD

3. Menyebutkan lambang angka 1-10

4. Mencocokkan angka menggunakan lambang angka.

Metode yang digunakan dalam penelitian ini adalah metode deskriptif.(Ali) Mengemukakan bahwa: "Metode penelitian deskriptif digunakan untuk memecahkan masalah yang sedang dihadapi pada masa sekarang, yang akan datang, dilakukan dengan langkah pengelolaan data, membuat gambaran tentang sesuatu dengan cara objektif mengadakan perbaikan-perbaikan."

Untuk analisis deskriptif menurut (Ali)adalah

$\%=\frac{\mathrm{n}}{\mathrm{N}} \mathrm{X} 100$

Keterangan:

$\mathrm{n}$ : nilai yang diperoleh

$\mathrm{N}$ : jumlah keseluruhan yang diperoleh

$\%$ : persentase

Berdasarkan rumus tersebut, maka untuk perhitungannya, sebagai berikut:

Keterangan:

N: Total Seluruh Siswa

$\mathrm{X}$ : Mulai Meningkat

Y: Meningkat Sesuai Harapan

$100 \%$ : Persentase

Dari data diatas dengan jumlah siswa ada 18 orang, diketahui bahwa siswa Belum Meningkat 
(BM) 0, siswa Mulai Meningkat (MM) 7 orang dan Meningkat Sesuai Harapan (MSH) 11 orang.

$$
\begin{aligned}
& \mathrm{BM}=0 / 18 \times 100 \%=0 \% \\
& \mathrm{MM}=7 / 18 \times 100 \%=38 \% \\
& \mathrm{MSH}=11 / 18 \times 100 \%=61 \%
\end{aligned}
$$

Dari hasil persentase diatas, diperoleh hasil bahwa penerapan kosakata bahasa pada anak usia dini mulai meningkat dengan persentase $38 \%$, dan penerapan kosakata bahasa pada anak usia dini dengan alat permainan edukatif meningkat sesuai harapan dengan persentase $61 \%$ maka dapat disimpulakan bahwa Alat permainan edukatif (APE) dapat diterapkan dalam meningkatkan kosakata bahasa pada anak usia dini.

Permainan bahasa adalah salah satu teknik pembelajaran kosakata mempunyai kelebihan tersendiri buat diaplikasikan di kelas, yakni proses pembelajaran yang berlangsung secara formal diintegrasikan menggunakan suasana rileks dan menyenangkan melalui aktivitas bermain bahasa. Hal ini senada yang dikemukakan oleh anak didik beserta pengajar membentuk pembelajaran yang lebih efektif, kreatif dan inovatif. Sehingga siswa lebih bersungguh-sungguh, lebih memahami dan menikmati proses pembelajaran bahasa di kelas sebagai kegiatan belajar-mengajar.

Proses pembelajaran dapat optimal bila guru mampu menyediakan sarana alat permainan yang mampu menstimulus seluruh perkembangan anak usia dini. Media pembelajaran dengan sistem permainan layak dipergunakan dalam proses pembelajaran karena dengan belajar sambil bermain dapat membuat suasana belajar lebih menyenangkan bagi siswa karena tidak membosankan selama proses belajar, siswa yang lebih aktif dan efisien dalam pencapaian tujuan pembelajaran.

Menurut (Nurlaili) alat permainan merupakan sumber belajar yang dirancang khusus dalam pembelajaran anak. Prinsip pembelajaran anak adalah bermain. Dengan demikian, bermainnya anak merupakan kegiatan belajar. Agar kegiatan bermain ini memberikan rasa senang dan kegembiraan bagi anak maka harus dilengkapi dan fasilitasi dengan tersedianya beragam jenis alat permainan, yang dirancang dalam rangka mengembangkan berbagai aspek perkembangan anak.

Dalam meningkatkan kosakata bahasa pada anak usia dini, Alat permainan edukatif (APE) sangat diperlukan karena dapat mempermudah guru menyampaikan suatu informasi atau pembelajaran yang ingin dicapai. Selain itu Alat permainan edukatif (APE) juga digunakan untuk mempermudah anak memahami pesan yang akan disampaikan.

\section{Simpulan}

Penguasaan kosakata merupakan aktivitas menguasai atau kemampuan mengetahui dan memakai istilah-istilah yang masih ada pada suatu bahasa, baik bahasa verbal juga tulisan. Perkembangan ilmu pengetahuan dan teknologi mendorong upaya pembaharuan pada pemanfaatan output-output teknologi pada proses belajar mengajar, sebagai akibatnya media merupakan bagian yang tidak terpisahkan berdasarkan proses belajar mengajar demi tercapainya tujuan pendidikan dalam biasanya dan tujuan pembelajaran pada sekolah dalam khususnya.

Media menjadi salah satu komponen pada aktivitas belajar mengajar yang dipakai pada pembelajaran yang dipilih atas dasar tujuan dan bahan pelajaran yang sudah ditetapkan, oleh karenanya pendidik menjadi subjek pembelajaran wajib bisa menentukan media dan asal pembelajaran yang tepat, sebagai akibatnya bahan pelajaran yang disampaikan bisa diterima siswa menggunakan baik.

Oleh sebab itu, pendidik memerlukan APE untuk melancarkan kegiatan belajar mengajar. Alat Permainan Edukatif juga merupakan media yang dibutuhkan anak untuk menstimulasi, motivasi, dan semangat belajarnya dalam lingkungan formal maupun non formal.

Alat permainan edukatif (APE) merupakan sarana yang dapat menstimulus aktivitas anak-anak untuk mempelajari sesuatu hal tanpa disadari oleh anak tersebut, baik melalui penggunaan teknologi modern maupun tradisional. Dari hasil persentase diatas, diperoleh hasil bahwa melalui alat permainan edukatif (APE) dapat meningkatkan kosakata bahasa pada anak usia dini mulai dengan persentase 38\%, dan melalui alat permainan edukatif dapat meningkatkan kosakata bahasa pada anak usia dini sesuai harapan dengan persentase $61 \%$. Sehingga dapat disimpulkan bahwa Alat Permainan Edukatif (APE) dapat meningkatkan kosakata bahasa pada anak usia dini. 


\section{Ucapan Terima Kasih}

Penulis mengucapkan terimakasih kepada mitra kami yitu TK Al-AFLAH Jakarta-Selatan yang telah memberikan motivasi dan bantuannya sehingga kegiatan penelitian ini terlaksana dengan baik.

\section{Daftar Rujukan}

Ali, M. Penelitian Kependidikan Prosedur dan Strategi. Angkasa, 1992.

Hapidin. "Konsep Dasar Manajemen Pendirian Lembaga TK/PAUD." Modul 1, 2011.

Khotijah. "Strategi Pengembangan Bahasa pada Anak Usia Dini." Elementary, 2016.

Krisnawan, Gusti Ngurah Aditya. "Rancang Bangun Aplikasi Game Edukasi Bahasa Inggris untuk Anak Berbasis Android." Konferensi Nasional Sistem Dan Informatika (KNS\&I), 2015.

Kuncoro, Adam Prayogo, et al. "Pengembangan Sistem Informasi Berbasis Website sebagai Media Pengelolaan Peminjaman dan Pengembalian Alat Laboratorium Fikes UMP." SATIN - Sains Dan Teknologi Informasi, 2019, doi:10.33372/stn.v4i2.396.

Markus, Nengsih, et al. "Penguasaan Kosakata Bahasa Indonesia Anak Usia 4-5 Tahun." FONEMA, 2018, doi:10.25139/fonema.v4i2.762.

Nur, Haerani, et al. "Permainan Paraga sebagai Olahraga Tradisional Masyarakat Suku Bugis Makassar di Sulawesi Selatan (Studi Fenomenologis Ditinjau Dari Aspek Keterampilan Gerak Dan Ketangkasan Fisik)." Jurnal Pendidikan Jasmani Dan Olahraga, 2017, doi:10.24832/jpnk.v18i4.99.

Nurlaili, Nurlaili. "Sumber Belajar dan Alat Permainan untuk Pendidikan Anak Usia Dini." $A l$ Fitrah: Journal Of Early Childhood Islamic Education, 2018, doi:10.29300/alfitrah.v2i1.1518.

Nurmadiah, Nurmadiah. "Strategi Pembelajaran Anak Usia Dini." Al-Afkar: Jurnal Keislaman \& Peradaban, 2016, doi:10.28944/afkar.v3i1.101.

Oktavianingsih, Eka. "Pengembangan Program Pelibatan Orang tua dalam Penyelenggaraan Pendidikan Anak Usia Dini." Journal of Early Childhood Care and Education, 2019, doi:10.26555/jecce.v1i2.231.

Sahjat, Sumarni, and Farida Samad. "Pelatihan Pembuatan Alat Permainan Edukatif (APE) Playdough sebagai Sumber Belajar." Jurnal PG-PAUD Trunojoyo: Jurnal Pendidikan dan Pembelajaran Anak Usia Dini, 2018, doi:10.21107/pgpaudtrunojoyo.v5i1.3687.

Santoso, Budi. "Cash Flow dalam Ekonomi Teknik." Budi2one.Blogspot.Com, 2013.

Suhendi, Enjang T. "Berbahasa, Berpikir, dan Peran Pendidikan Bahasa." Proceedings Education and Language International Conference, 2017. 